\title{
A New Look at Modeling Surface Heterogeneity: Extending Its Influence in the Vertical
}

\author{
ANDREA MOLOD* \\ Department of Earth and Planetary Sciences, The Johns Hopkins University, Baltimore, Maryland \\ HAYDEE SALMUN \\ Department of Geography, Hunter College of the City University of New York, New York, New York \\ DARRYN W. WAUGH \\ Department of Earth and Planetary Sciences, The Johns Hopkins University, Baltimore, Maryland
}

(Manuscript received 21 June 2002, in final form 4 February 2003)

\begin{abstract}
Heterogeneities in the land surface exist on a wide range of spatial scales and make the coupling between the land surface and the overlying boundary layer complex. This study investigates the vertical extent to which the surface heterogeneities affect the boundary layer turbulence. A technique called "extended mosaic" is presented. It models the coupling between the heterogeneous land surface and the atmosphere by allowing the impact of the subgrid-scale variability to extend throughout the vertical extent of the planetary boundary layer. Simulations with extended mosaic show that there is a GCM level at which the distinct character of the turbulence over different land scene types is homogenized, which the authors call the model blending height. The behavior of the model blending height is an indicator of the mechanism by which the surface heterogeneities extend their direct influence upward into the boundary layer and exert their influence on the climate system. Results are presented that show the behavior of the model blending height and the relationships to atmospheric and surface conditions. The model blending height is generally one-third to one-half of the planetary boundary layer height, although the exact ratio varies with local conditions and the distribution of the underlying vegetation. The model blending height also increases with canopy temperature and sensible heat flux and is influenced by the amount of variability in the surface vegetation and the presence of deciduous trees.
\end{abstract}

\section{Introduction}

In order to understand and predict the behavior of the earth's climate system it is important to understand how energy, water, carbon, and nitrogen are exchanged between the atmosphere and the terrestrial biosphere. The effects of these exchanges may extend beyond the regions in which they are initiated by inducing modifications of the large-scale circulation. In order to accurately predict climate and climate change it is therefore neccessary to realistically calculate the land surface-atmosphere exchanges in global climate models. These calculations are further complicated by the fact that the character of the land surface is highly variable, due, for example, to the variability of vegetation cover, * Additional affiliation: Data Assimilation Office, Goddard Space
Flight Center, Greenbelt, Maryland.

Corresponding author address: Andrea Molod, Dept. of Earth and Planetary Sciences, The Johns Hopkins University, 3400 N. Charles St., Baltimore, MD 20218.

E-mail: molod@rua.eps.jhu.edu the types of terrain, soil texture and wetness, the amount of cloud cover and precipitation, and the extent of urban areas. These heterogeneities will determine in part the impact on climate of land use changes such as deforestation, urbanization, and desertification. The scale of these heterogeneities may be smaller, and in some cases much more so, than the characteristic grid scale in most current general circulation models (GCMs) used in climate studies.

The influence of the surface heterogeneities extends vertically in the atmosphere up to some level, generally above the surface layer and within the planetary boundary layer, as indicated by observational and modeling studies (Claussen 1995; Mahrt 2000 and papers cited therein). These studies characterize the vertical influence in terms of the blending height—defined as the level inside the planetary boundary layer above which the flow becomes horizontally homogeneous in the absence of other influences (Wieringa 1986). Using field measurements and scaling arguments, it has been established that this blending height is variable, depends mostly on the nature of the surface roughness elements, the bouyancy, 
and the horizontal scale of heterogeneity (Parlange and Katul 1995; Brutsaert 1998; Mason 1988). A comprehensive survey of different blending height estimates under different atmospheric conditions was presented by Mahrt (1996), where he reported that the blending height can be as high as the height of the planetary boundary layer, or even higher for an unstable atmosphere under the influence of strong surface heating.

The effects of land surface heterogeneities can be characterized as "aggregation" effects and "dynamical" effects, the first arising directly from spatial heterogeneity in the land surface and the second associated with the small-scale (micro- and mesoscale) circulations induced by heterogeneous surfaces (Giorgi and Avissar 1997). Aggregation effects may arise, for instance, over a terrain that is partially covered by vegetation, or partially irrigated, resulting in a patch with higher latent heat fluxes than the surrounding terrain. For example, Cotton and Pielke (1992) discussed observations that clearly showed the marked difference in potential temperature and moisture mixing ratio between an irrigated and a dry terrain. Based on these observations, calculations showed that the energy for deep convection was higher over the wetter terrain due to the higher equivalent potential temperature. The occurrence of deep convection over the wetter areas of the domain is considered an aggregation effect of spatial heterogeneity, and maintaining the integrity of these types of heterogeneities throughout the depth of the boundary layer and not "averaging them out" is important to properly modeling aggregation effects.

Dynamical effects may arise under certain synoptic conditions, when the patches in the terrain are larger than about $5-10 \mathrm{~km}$ in size, and the surface fluxes are organized into mesoscale patterns (see, e.g., Avissar and Schmidt 1998). These organized mesoscale circulations are induced by mesoscale-sized contrasts in sensible heat flux, due to heterogeneities in vegetation, soil, terrain elevation, or irrigation practices, for example. These circulations can affect the vertical structure of the planetary boundary layer, the turbulent fluxes, and may induce localized areas of shallow convection (Chen and Avissar 1994).

Both effects of heterogeneity are important in modeling land surface processes and interactions within climate models. However, it is only the aggregation effects that are captured in almost all present-day GCMs. Some GCM parameterizations of dynamical effects have been developed (Avissar and Chen 1993), but are not in current use. One of the existing techniques employed in GCMs to capture the aggregation effects is the "composite" technique, which accounts for the subgrid-scale variability by specifying soil and vegetation parameters that represent a homogeneous composite vegetated surface (e.g., Viterbo and Beljaars 1995). This modeling of each GCM grid square as having homogeneous, albeit composite vegetation and soil characteristics does not allow for the direct propagation of the independent char- acteristics of each vegetation type into the atmosphere at all. Another commonly used technique is the "mosaic" technique, which calculates separate heat and moisture balance equations for each vegetation type contained within a GCM grid square (e.g., Koster and Suarez 1992b). Mosaic does not account for the vertical influence of the land surface heterogeneities beyond the height of the surface layer. Other techniques for handling land surface heterogeneities include the "dominant" technique (e.g., Dickinson et al. 1986), combinations of composite and mosaic (e.g., Hess and McAvaney 1998), a "mixture" technique (Sellers et al. 1986), and a statistical-dynamical approach (e.g., Entekhabi and Eagleson 1989). In all of these techniques, however, the direct vertical influence of surface heterogeneities is confined to the surface layer or below.

As discussed earlier in this paper, scaling arguments and observations suggest that the effects of the heterogeneities are felt well into the planetary boundary layer. Hence, the limits on the vertical influence of surface heterogeneities imposed by the previous techniques may well constitute an important limitation to capturing the effectiveness of the communication between the land surface heterogeneity and the atmosphere (Mahrt 2000). In this paper we present a technique called extended mosaic, which overcomes this restriction and allows the impact of aggregation effects of subgrid-scale variability to extend throughout the vertical extent of the planetary boundary layer.

In the next section we describe the extended mosaic technique, followed by a section defining the model blending height. In section 4 we present and examine the variability of the model blending height and the relationship with other atmospheric quantities using a GCM simulation with extended mosaic, and the study is summarized in the final section, where we present early results from comparisons between extended mosaic and the standard mosaic technique.

\section{The extended mosaic technique}

Extended mosaic (EM) is a new technique that follows the mosaic approach and extends the direct influence of surface heterogeneities upward throughout the entire depth of the turbulent atmospheric boundary layer. The EM technique is used to couple the land surface model to the turbulent atmospheric boundary layer. The essence of this technique is the interplay between processes that occur in grid space and processes that occur in tile space, and the extension of that interplay throughout the depth of the turbulent layer. The EM technique was originally developed for use in the Goddard Earth Observing System (GEOS)-Terra GCM (Molod 1999), which includes a parameterization of turbulent fluxes of momentum, heat, water vapor, and turbulent kinetic energy at the surface and at each GCM level, as described in detail by Helfand and Labraga (1988) and Helfand and Schubert (1995). The GEOS-Terra GCM also in- 
cludes the Koster-Suarez land surface model (Koster and Suarez 1992b), which is a soil-vegetation-atmosphere-transfer model based on the Simple Biosphere Model of Sellers et al. (1986).

In both the standard and extended mosaic approaches, the subgrid-scale variability of the surface is modeled by viewing each GCM grid cell as a mosaic of independent vegetation stands, using linear aggregation (disaggregation) formulas for links to the GCM grid. The vegetation stands, or tiles, interact only through the coupling to the GCM atmosphere, so there is no direct interaction between the different tiles. This modeling assumption is valid when the horizontal fluxes of heat and moisture are small compared to the vertical fluxes (Avissar and Pielke 1989; Koster and Suarez 1992a). The description of the surface in this approach is presented schematically in the lowest level of Fig. 1, where a hypothetical GCM grid square containing the tiles that describe the mix of surface scene types is shown. In this grid square, all of the bare soil portions of the grid box are treated as though they are juxtaposed, as are all of the deciduous trees, evergreen trees, and shrubs. Each of these types is assigned a fraction of areal coverage, and the grid-box averaged quantities are computed using an area-weighted linear aggregation.

In the EM approach, the tiles are extended vertically throughout the depth of the model atmosphere. The direct influence of the surface heterogeneity is extended upwards due to the differences in the characteristics of the turbulent boundary layer above each tile. This is illustrated schematically in Fig. 1, where the heterogeneity at each GCM model level (LM, LM-1, etc.) is conceptualized in terms of the same tiles that characterize the surface. The airmass properties may become homoge- nized at any height up to or above the boundary layer height, and each individual tile retains its separate character up to that level. The underlying modeling assumption here, as an extension of the assumption neccessary at the surface layer, is that throughout the atmospheric column the tiles "feel each other" only through the interaction with the surrounding mean flow. This assumption is valid when the horizontal turbulent fluxes throughout the depth of the boundary layer are small compared to the vertical fluxes. There is some observational justification for this assumption (Yamada 1977).

The key element to understanding the homogenization of turbulent air properties in an EM approach is the interplay between the grid-resolved processes and the tile-resolved processes. The grid-resolved processes are horizontal and vertical advection, radiative heating and cumulus convection, and the tile-resolved process is turbulent mixing. The tile space tendency due to diffusion impacts the grid space variables, and the gridscale tendencies impact the tile space variables, thus establishing the interplay.

In EM we write the total grid-space tendency of an atmospheric-state variable, $G_{\alpha}$, as the sum of the tendency due to grid-space terms and the aggregated tilespace terms [Eq. (1)]. The terms in the equations of motion that arise from the parameterization of turbulent processes are the "turbulent tendency" terms, and are similar for all the atmospheric state variables. In order to evaluate a turbulent tendency of an atmospheric state variable, we account for the influence of processes that occur in both grid and tile space. The grid-space tendencies are functions of grid-space variables only, while the tile-space tendencies are functions of both grid-space and tile-space variables. This can be represented schematically by the following expression:

$$
\left.\left(\frac{\partial G_{\alpha}}{\partial t}\right)\right|_{\text {total }}=\left.\left(\frac{\partial G_{\alpha}}{\partial t}\right)\right|_{\text {grid }}\left(G_{\alpha_{1}}, G_{\alpha_{2}}, \ldots\right)+\left.\frac{1}{N} \sum_{n=1}^{N}\left(\frac{\partial G_{\alpha}}{\partial t}\right)\right|_{\text {turb }} ^{n}\left(G_{\alpha_{1}}, G_{\alpha_{2}}, \ldots, \mathcal{T}_{\beta_{1}}^{n} \cdot \mathcal{T}_{\beta_{2}}^{n}, \ldots\right) \times f_{n}
$$

where the $G_{\alpha}$ 's are the grid-space state variables, the $\mathcal{T}_{\beta}^{n}$ 's are the tile-space variables, and the summation is over $N$ tiles, where $\mathrm{n}$ is the tile index. The subscript grid refers to grid-space calculations, and the subscript turb refers to turbulent processes, which occur in tile space. The grid-space state variables are the horizontal components of velocity, the potential temperature, the specific humidity, the surface pressure, and any passive scalar. The tile-space variables consist of surface fields (canopy and deep soil temperatures, three levels of soil moisture, the canopy reservoir capacity, the snow depth and the canopy specific humidity) and fields defined on all GCM levels (turbulent kinetic energy and the turbulence-induced liquid water mixing ratio and cloud fraction). The second term on the right-hand side of Eq.
(1) contains the tile-space turbulent tendency, and is proportional to the vertical divergence of the turbulent flux, namely,

$$
\left.\left(\frac{\partial G_{\alpha}}{\partial t}\right)\right|_{\text {turb }} ^{n} \propto \frac{\partial}{\partial z}\left(\overline{w^{\prime} g_{\alpha}^{\prime}}\right)^{n}
$$

where $g_{\alpha}^{\prime}$ is the fluctuating component of $G_{\alpha}$ and $w^{\prime}$ is the (turbulent) vertical component of the velocity field. This term, and all of the turbulent fluxes, the turbulent kinetic energy and turbulent variances (i.e., all the turbulent second moments) are modeled by the MellorYamada level-2.5 scheme used in the GCM as functions of turbulent quantities (tile-space variables) and mean flow quantities (grid-space variables). 


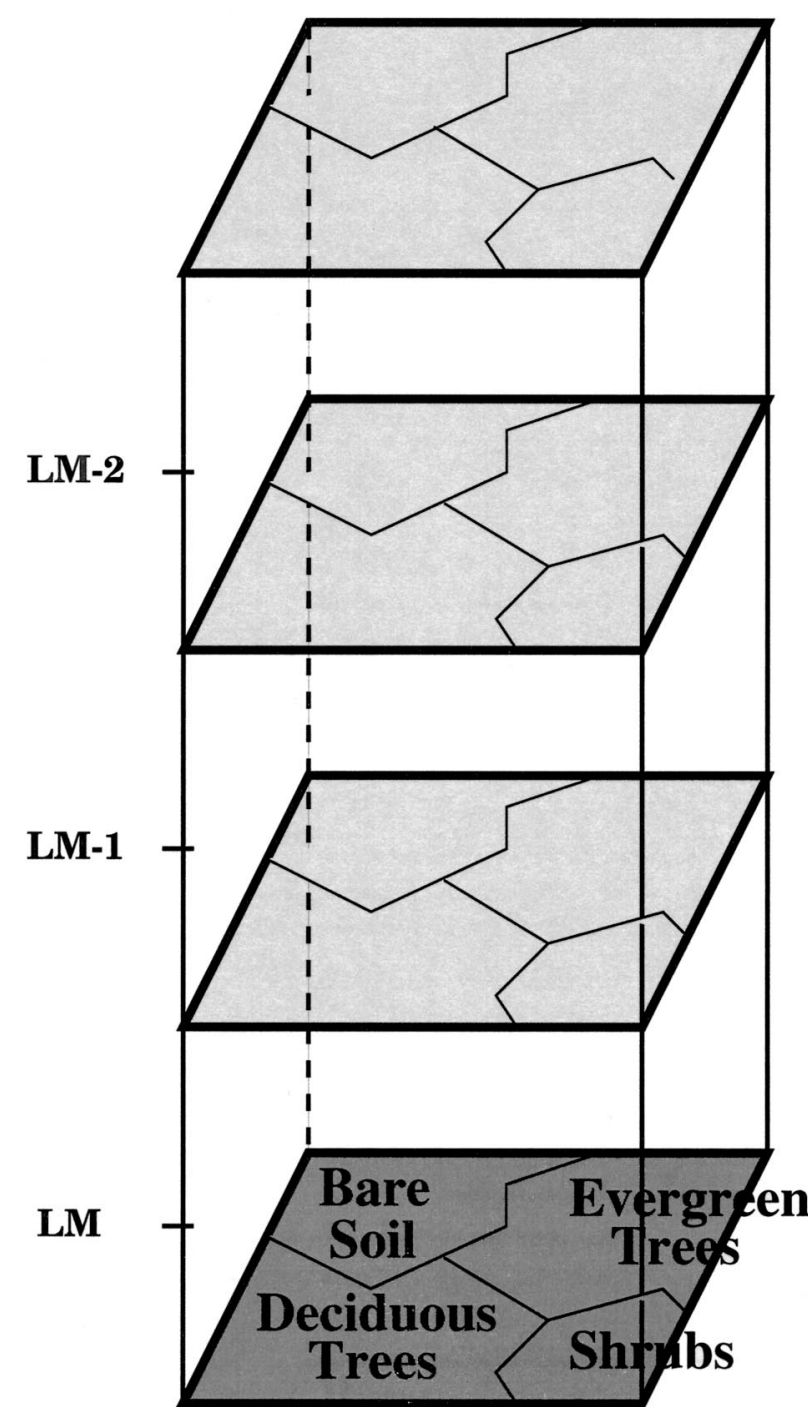

FIG. 1. Schematic of the extended mosaic technique. The vertical axis indicates the GCM model levels, where LM is the lowest level and the level number increases as we ascend in the column.

In addition to the vertical extent of tile space, there is another fundamental difference between the original mosaic approach and EM. This difference is in the handling of the tile-space surface fluxes into the bottom model layer. In EM it is the divergence of turbulent fluxes, or the turbulent tendency itself, which is computed in tile space and aggregated for use by the GCM, whereas in mosaic the surface fluxes are aggregated, and a grid-space divergence is computed.

In a full implementation of EM the atmospheric-state variables would be retained at both tile space to compute turbulent diffusion and grid space to compute grid-space processes. The implementation of EM described above, however, does not retain the full set of atmosphericstate variables in tile space from one time step to the next, rather the tile space boundary layer structure is retained in the predicted turbulent second moments. This simplification may provide an additional homogenizing influence. To the extent that the tile space structure of the overlying boundary layer is preserved by the turbulent moments, EM as presently implemented will appropriately account for the vertical influence of surface heterogeneities.

\section{The model blending height}

In an analogy to the blending height concept, we define here the model blending height $(\mathrm{MBH})$ as the model level above the heterogeneous land surface at which it is assumed that the turbulent mixing has homogenized the airmass properties. This is the level above which the flow over the different tiles begins to appear uniform. Each of the aggregation techniques described above implies a different extent of the vertical influence of surface heterogeneity in the GCM. We can view the composite methodology as setting an $\mathrm{MBH}$ at the ground and the mosaic approach as setting an $\mathrm{MBH}$ at the top of the surface layer. The EM approach is the only approach that has a variable $\mathrm{MBH}$. The extension of the concept of a blending height to larger scales was briefly mentioned in Bringfelt et al. (1999), where it is explicitly stated that mosaic assumes that the blending height is at the surface layer, and that this might not be an adequate representation of the impact of surface heterogeneity. The recognition that mosaic cannot account for the extended vertical influence of the land surface variability was noted earlier by Koster and Suarez (1992a). The limitations of mosaic in this regard was suggested by the results of a study by Mölders et al. (1996). They compared mosaic to an explicit subgridscale model, and reported that the differences are small in the middle to upper troposphere and that these differences increase with proximity to the surface starting inside the atmospheric boundary layer. The extended mosaic technique attempts to address these limitations of mosaic discussed here.

To define a measure of the $\mathrm{MBH}$ we examined the results of a year-long GCM simulation using EM (see section 4 for details). Typical profiles of the turbulent fluxes of temperature, momentum, and humidity over each tile in a grid box are shown in Fig. 2. Figure $2 \mathrm{a}$ shows the profiles of $\overline{w^{\prime} \theta^{\prime}}$ and $\overline{w^{\prime} q^{\prime}}$ at 0300 UTC over a grid point located in the northern steppes $\left(58^{\circ} \mathrm{N}, 75^{\circ} \mathrm{E}\right)$. This particular grid box has three tiles, a broadleaf deciduous trees tile, a bare soil tile, and a needleaf trees tile. The values of the flux emanating from the surface layer (those at the bottom $\sigma$-level) are very different from tile to tile. We also see that the differences in the turbulent fluxes between the tiles have been propagated upward, as the fluxes are still distinct aloft. At higher levels, values of $\overline{w^{\prime} \theta^{\prime}}$ approach each other until approximately $\sigma=0.975$ where the fluxes are almost indistinguishable. At this "homogenized" level, however, the fluxes are still significant. The turbulent boundary 

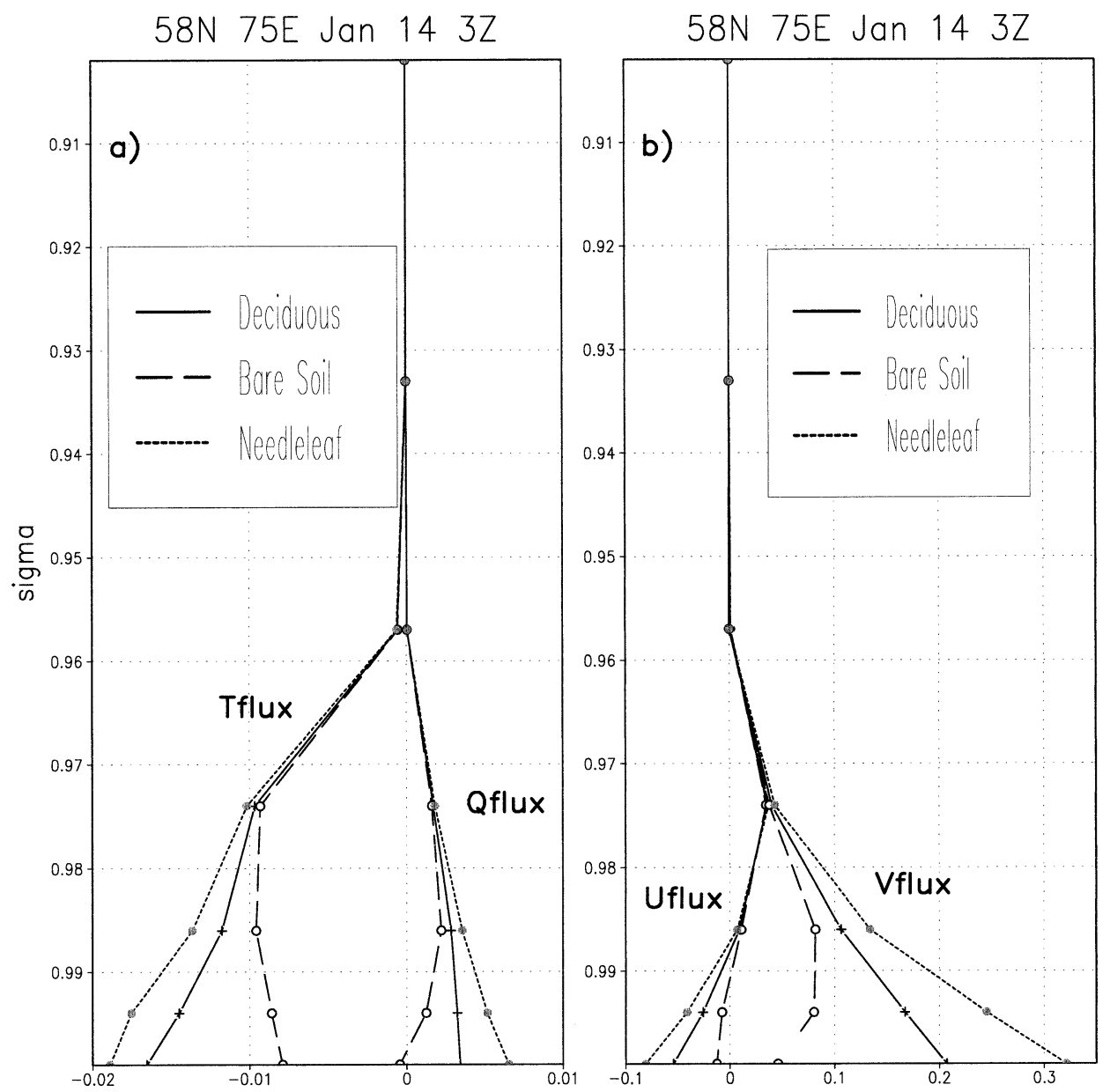

FIG. 2. Typical turbulent flux profiles for the tiles in a grid box. (a) Heat and moisture flux, and (b) umomentum and v-momentum flux for typical values of $V_{s}$. The units of the horizontal axis indicate the value of the appropriate turbulent flux, where heat flux is in $\mathrm{kg} \mathrm{m}^{-2} \mathrm{~s}^{-1} \mathrm{~K}$, moisture flux is in $\mathrm{kg} \mathrm{m}^{-2} \mathrm{~s}^{-1}$ $\mathrm{dg} \mathrm{kg}^{-1}$, and momentum flux is in $\mathrm{kg} \mathrm{m}^{-1} \mathrm{~s}^{-2}$. The vertical axis is model $\sigma$ level, which can be multiplied by 1000 to approximate pressure in mb.

layer height is defined in the GCM as the level at which the turbulent fluxes decay below $10 \%$ of their column maximum value, and this does not occur until $\sigma=0.95$. Figure $2 \mathrm{~b}$ shows the turbulent fluxes of momentum for the same location and time, and these are seen to exhibit the same character. This qualitative sense of the location of the $\mathrm{MBH}$ can be quantified by defining a measure of the surface variability and some threshold of variability below which the fluxes over different tiles may be considered homogenized. The measure of tile-to-tile variability $(V)$ at any level is $V=F_{\max }-F_{\min }$, where $F_{\max }$ and $F_{\min }$ are the maximum and minimum values of the turbulent flux among all the tiles, respectively. The measure of surface variability that we use is $V_{s}=\max \left(F_{\max }\right.$ $\left.-F_{\text {min }}\right)$, where max of the difference refers to the level at which the difference is maximum (usually at the surface). As we ascend in the atmospheric column, $V$ decreases with height relative to its maximum value, $V_{s}$, and we define the $\mathrm{MBH}$ as the level at which it descends below the threshold.
To determine the proper threshold, profiles of turbulent fluxes and the resulting $\mathrm{MBH}$ were examined under many atmospheric and geographic conditions. The threshold varies with the magnitude of our measure of the surface variability, $V_{s}$, which itself varies between 0.0 and $0.5 \mathrm{~kg} \mathrm{~m}^{-2} \mathrm{~s}^{-1} \mathrm{~K}$. For the vast majority of profiles and conditions, which constitute $88 \%$ of the total profiles, the threshold value for $V$ is $20 \%$ of $V_{s}$. For the profiles in Figs. $2 \mathrm{a}$ and $2 \mathrm{~b}$, the $20 \%$ threshold resulted in an $\mathrm{MBH}$ at $\sigma=0.975$, which is indeed where the fluxes begin to appear uniform. For conditions under which the fluxes and the surface variability were extremely large or extremely small, different thresholds for $V$ were necessary to ensure that the algorithm for the $\mathrm{MBH}$ generates the proper value. An example of profiles for which $V_{s}$ was extremely large $\left(>0.2 \mathrm{~kg} \mathrm{~m}^{-2}\right.$ $\mathrm{s}^{-1} \mathrm{~K}$ for heat fluxes), is shown in Fig. 3a. A threshold of $20 \%$ would place the $\mathrm{MBH}$ at $\sigma=0.955$, which is clearly too low. For these profiles, which constitute only $7 \%$ of the total profiles, the threshold used is $5 \%$ of $V_{s}$. 

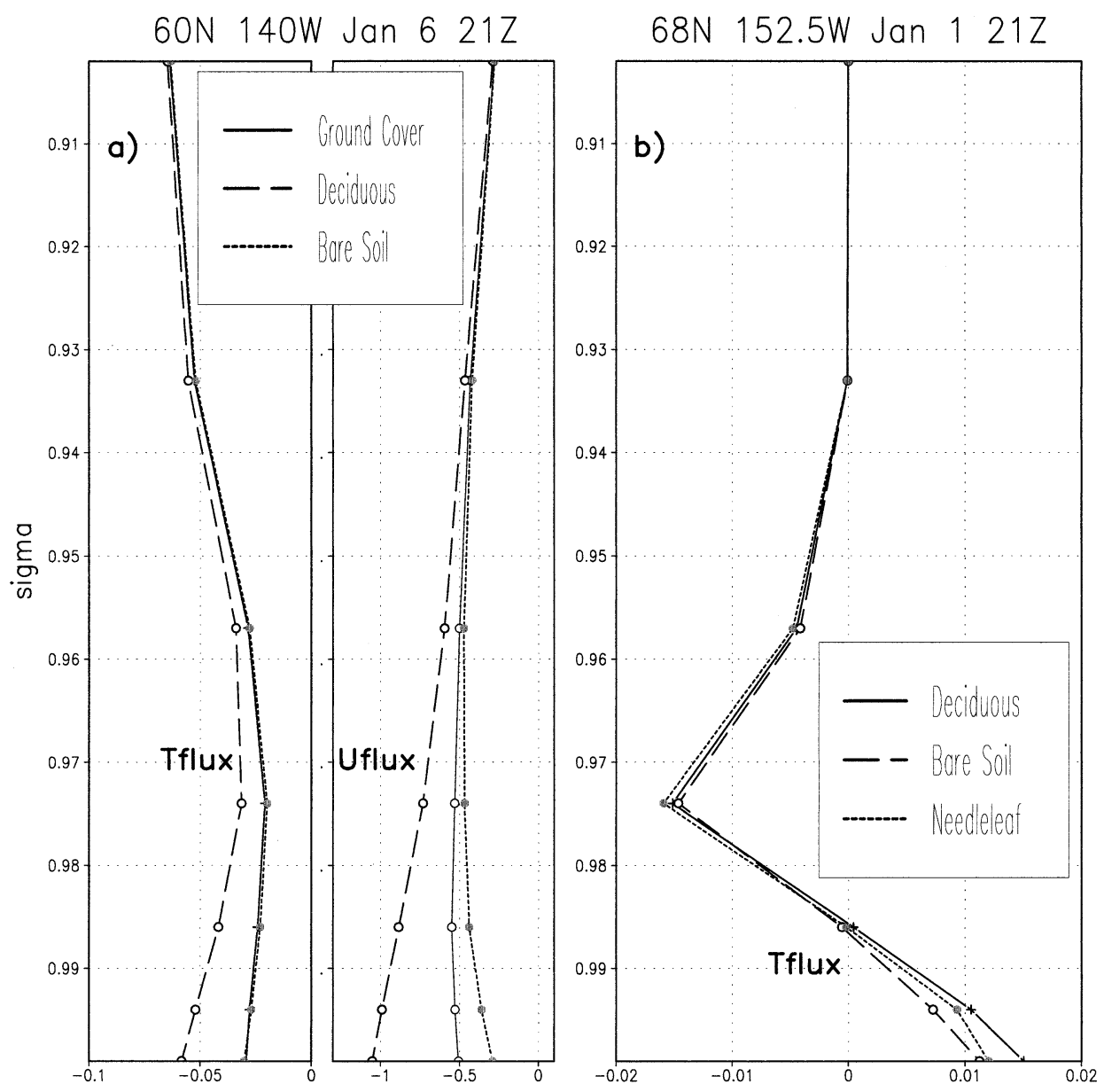

Fig. 3. Turbulent flux profiles neccessitating extreme threshold values. (a) Heat and momentum flux for a case in which $V_{s}$ is large, and (b) heat flux for a case in which $V_{s}$ is small. The units of the horizontal axis indicate the value of the appropriate turbulent flux, where heat flux is in $\mathrm{kg} \mathrm{m}^{-2} \mathrm{~s}^{-1} \mathrm{~K}$, and momentum flux is in $\mathrm{kg} \mathrm{m}^{-1} \mathrm{~s}^{-2}$. The vertical axis is model $\sigma$ level, which can be multiplied by 1000 to approximate pressure in $\mathrm{mb}$.

An example of profiles for which the fluxes and the surface variability were extremely small $(<0.006 \mathrm{~kg}$ $\left.\mathrm{m}^{-2} \mathrm{~s}^{-1} \mathrm{~K}\right)$, is shown in Fig. 3b. The $20 \%$ threshold would set the $\mathrm{MBH}$ at $\sigma=0.935$, which is clearly too far above the level at which the fluxes merge. For these profiles, which constitute roughly $4 \%$ of the total profiles, the threshold used is $65 \%$ of $V_{s}$, and the MBH is at $\sigma=0.985$. Finally, another threshold of $80 \%$ of $V_{s}$ was needed for a very small number of profiles, roughly $1 \%$ of the cases, in which $V_{s}$ is near zero $(<0.001 \mathrm{~kg}$

TABLE 1 . Range of surface variability $V_{s}$ calculated with turbulent heat fluxes in units of $\mathrm{kg} \mathrm{m}^{-2}$.

\begin{tabular}{ccc}
\hline \hline$V_{s}$ & Threshold $\%$ & $\begin{array}{c}\text { Percent of cases } \\
\text { included }\end{array}$ \\
\hline$V_{s}<0.001$ & 80 & 1 \\
$0.001<V_{s}<0.006$ & 65 & 4 \\
$0.006<V_{s}<0.2$ & 20 & 88 \\
$0.2<V_{s}$ & 5 & 7 \\
\hline
\end{tabular}

$\left.\mathrm{m}^{-2} \mathrm{~s}^{-1} \mathrm{~K}\right)$. The thresholds for each range of $V_{s}$ are listed in Table 1. With this choice of thresholds, along with our choice of $V_{s}$ as the measure of surface variability, we chose to define the MBH based on heat fluxes alone. Calculations of the MBH were also performed based on the moisture and momentum fluxes, and the resulting values were almost indistinguishable from those based on the heat fluxes.

Our algorithm to estimate the MBH is consistent with the ideas used to estimate the blending height (Mahrt 2000). These different approaches to assessing a measure of the level of the blending height all involve some measure of the surface variability and the level at which it decays below some threshold. One such measure involves a threshold value for the variance of the skin temperature normalized by some reference potential temperature, $\sigma_{T_{s}} / \Theta_{0}$. Another measure involves the variance of some turbulent flux divided by the flux, $\sigma_{F} / F$. In the context of our GCM study using the variance as the measure of surface variability is not suitable for a 
TABLE 2. GEOS-Terra GCM surface type designation.

\begin{aligned} & \hline \hline Type Vegetation designation \\ & \hline 1 Broadleaf evergreen trees \\ & 2 Broadleaf deciduous trees \\ & 3 Needleleaf trees \\ & 4 Ground cover \\ & 5 Broadleaf shrubs \\ & 6 Dwarf trees (tundra) \\ & 7 Bare soil \\ & 8 Desert (bright) \\ & 9 Glacier \\ & 10 Desert (dark) \\ & 100 Ocean \\ & \hline\end{aligned}

mosaic scheme involving three to four tiles in a grid box. Just like our measure of the surface variability, these measures of surface variability do not depend exclusively on the vegetation characteristics themselves. The physical characteristics of the land surface, such as the surface roughness and the soil hydraulic conductivity, are constant in time or vary on monthly timescales. The measures defined earlier in this paper depend on the local conditions as well, which may vary on many shorter and longer timescales. For example, under extreme cold atmospheric conditions the surface fluxes are minimal, and under wet conditions the evaporation proceeds at its potential rate. Either of these conditions will result in the suppression of any differences in physical characteristics and a reduced surface variability.

\section{Characterization of the MBH}

We now examine the spatial and temporal variability of the MBH and the relationship with other quantities using a year-long segment of a 27-month simulation performed with the EM technique as implemented in the GEOS-Terra GCM. The simulation is from December 1997 to March 2000 and is forced with observed weekly varying sea surface temperatures. The surface types used in this experiment are listed in Table 2. The data for percent of the grid cell occupied by any surface type were derived from the surface classification of Defries and Townshend (1994), and information about the location of permanent ice was obtained from the classifications of Dorman and Sellers (1989). The resulting vegetation map can be found Molod and Salmun (2002; their Fig. 2). In general, most grid boxes are characterized by approximately four different scene types (tiles). Several of the vegetation characteristics-namely, the leaf area index, greenness fraction, and surface roughness length - vary from month to month, while the others are constant throughout the year. The simulation results of 1998, for which an extensive diagnostic output in tile space was generated, were used to examine the EM technique by analyzing the behavior of the $\mathrm{MBH}$. We focus on the relationships between the MBH and other relevant physical parameters, such as the planetary boundary layer (PBL) height, the surface tem- perature and fluxes, and the type and distribution of underlying vegetation. To illustrate these relationships, we will present monthly averages of global fields and annual time series for representative points around the globe.

December-January-February (DJF) seasonal mean values of MBH, PBL, and the ratio MBH/PBL, given in pressure thickness above the surface, are shown in Fig. 4. The PBL height in the GCM is the level at which the turbulent kinetic energy decays below $10 \%$ of its maximum value in the air column, and there is therefore no a priori relationship between the MBH and the PBL height. The plots in Fig. 4 show that the MBH is variable, is above the surface layer, and is related to the PBL height but does not follow it exactly. The values of $\mathrm{MBH}$ range from 10 to near $40 \mathrm{mb}(100-400 \mathrm{~m}$, approximately). The geographic locations where the MBH is low, which are indicated by the blue areas of Fig. 4a, are the Tibetan Plateau, the Rocky Mountains, the Amazon basin, central Africa, and Siberia. The low MBH corresponds to low PBL values (the light blue regions in Fig. 4b) in all of these regions except for the Amazon, where the low MBH is associated with a relatively homogeneous terrain. Over the regions totally snow-covered in wintertime, the low MBH values may also be due to the potentially homogenizing effect of the snow. Regions where the MBH is high during DJF are the Southern Hemisphere midlatitude areas, where it is summertime, and where the PBL values are also high. There is another band of high MBH values at approximately $45^{\circ} \mathrm{N}$ latitude across the North American, European, and Asian continents. There is some indication of a local maximum in PBL height at these locations, as well as a transition of vegetation types at that latitude. There is also a local maximum in $\mathrm{MBH}$ in the Sahel region of Africa, related to the behavior of the PBL.

The ratio of MBH to PBL is always less than 1 (Fig. $4 \mathrm{c}$ ), ranging from 0.05 to greater than 0.9 , indicating that the MBH is always below the PBL. The global mean ratio is approximately $0.2-0.3$. There is a monotonic decrease in the ratio of MBH to PBL in the Northern Hemisphere from high latitudes (ratio near 0.9) to low latitudes (ratio near 0.15), except in the eastern United States. The large change in ratio is the result of a PBL thickness, which increases more rapidly than the MBH from north to south across these regions. In general, the ratio is low in the Southern Hemisphere, due to the high summertime PBL values. There is a local minimum in the ratio over the eastern United States, which corresponds to the local maximum in the PBL height (with a similar contour shape). In addition, there is a local minimum in the ratio over Sahel, where the PBL height is very high (greater than $300 \mathrm{mb}$ ). The ratio increases north of Sahel, due to the more rapid dropoff of the PBL height than the MBH.

The corresponding plots for June-July-August (JJA) are shown in Fig. 5. These plots also show that the MBH 


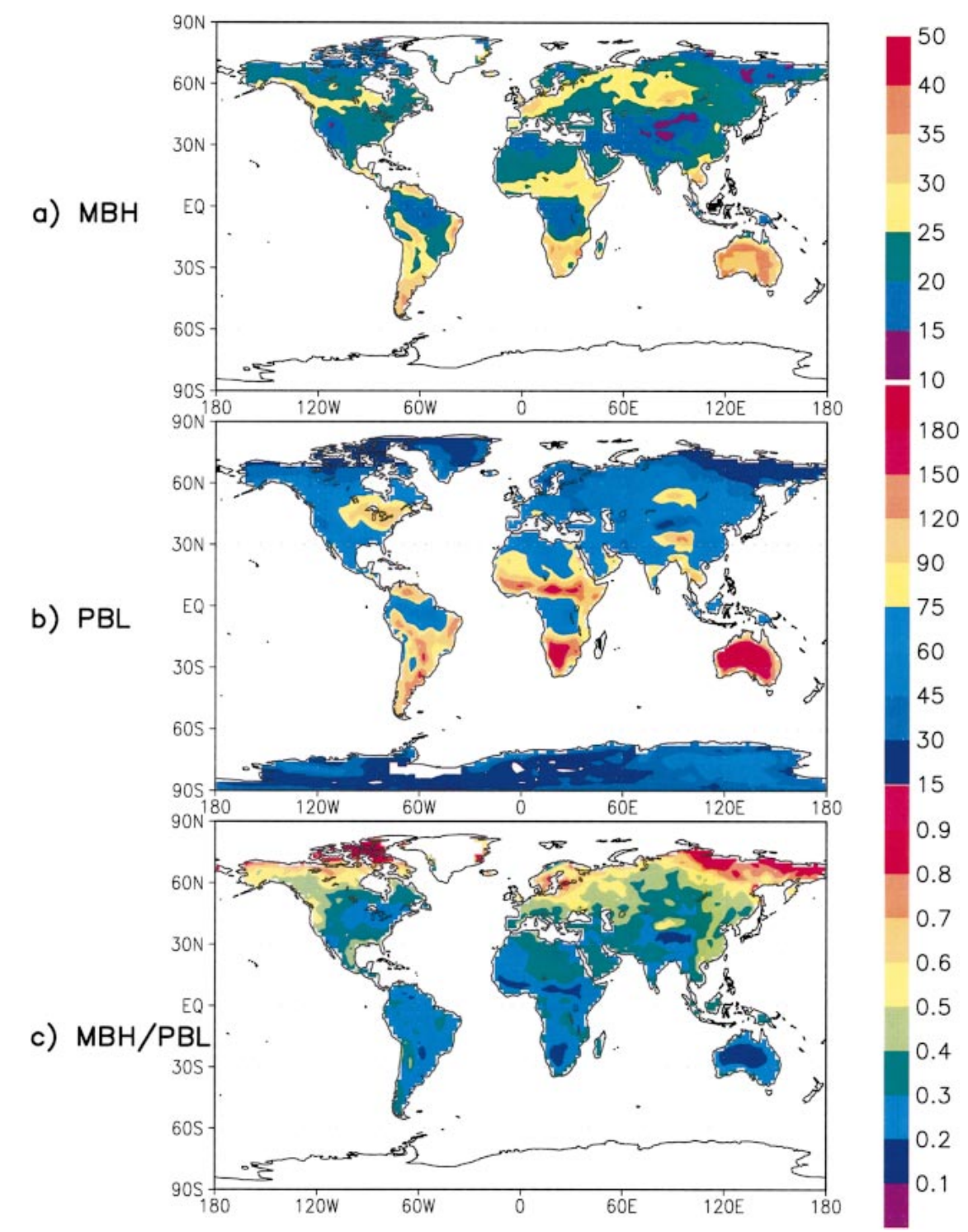

FIG. 4. Dec-Jan-Feb averaged model blending height and planetary boundary layer depth. (a) Model blending height in mb, (b) planetary boundary layer depth, also in mb, and (c) ratio of $\mathrm{MBH}$ to PBL (dimensionless). The contour levels are indicated in the color bar to the right.

is variable, and lies above the surface layer and inside the PBL. Some of the areas where the MBH is high correspond to high PBL values, such as the deserts of Sahara, Gobi, Saudi Arabia, and the southwestern United States, and regions in southern Africa and just south of the Amazon. An additional band of high MBH values exists at approximately $35^{\circ}-40^{\circ} \mathrm{N}$ latitude, stretching across Canada, Europe, and Asia. These high MBH values do not correspond to local maxima in the PBL height, rather they correspond in the shape of the contour to areas where there is a change in the nature of the vegetation (see Molod and Salmun 2002, their Fig. 2 ). In these regions the vegetation changes from a combination of bare soil and dwarf trees to predominantly needleleaf trees. The geographical locations where the
MBH is low are the Amazon, where the variability of the vegetation is small, and the Andes and the Tibetan Plateau, where the altitude and the cold temperatures limit the height of the PBL. There is also a local minimum in MBH in the southern tip of Africa, and another in central South America, just south of the local maximum. The ratio of $\mathrm{MBH}$ to $\mathrm{PBL}$ values is generally lower than in the Northern Hemisphere wintertime, with the lowest values (less than 20\%) corresponding to the highest values of PBL height. Except for southern Africa, the ratios are higher in the Southern Hemisphere (winter hemisphere) than in the summer hemisphere.

In general the $\mathrm{MBH}$ values differ more from the PBL height values in JJA than in DJF. The evolution of these fields throughout the year (not shown) indicates that the 


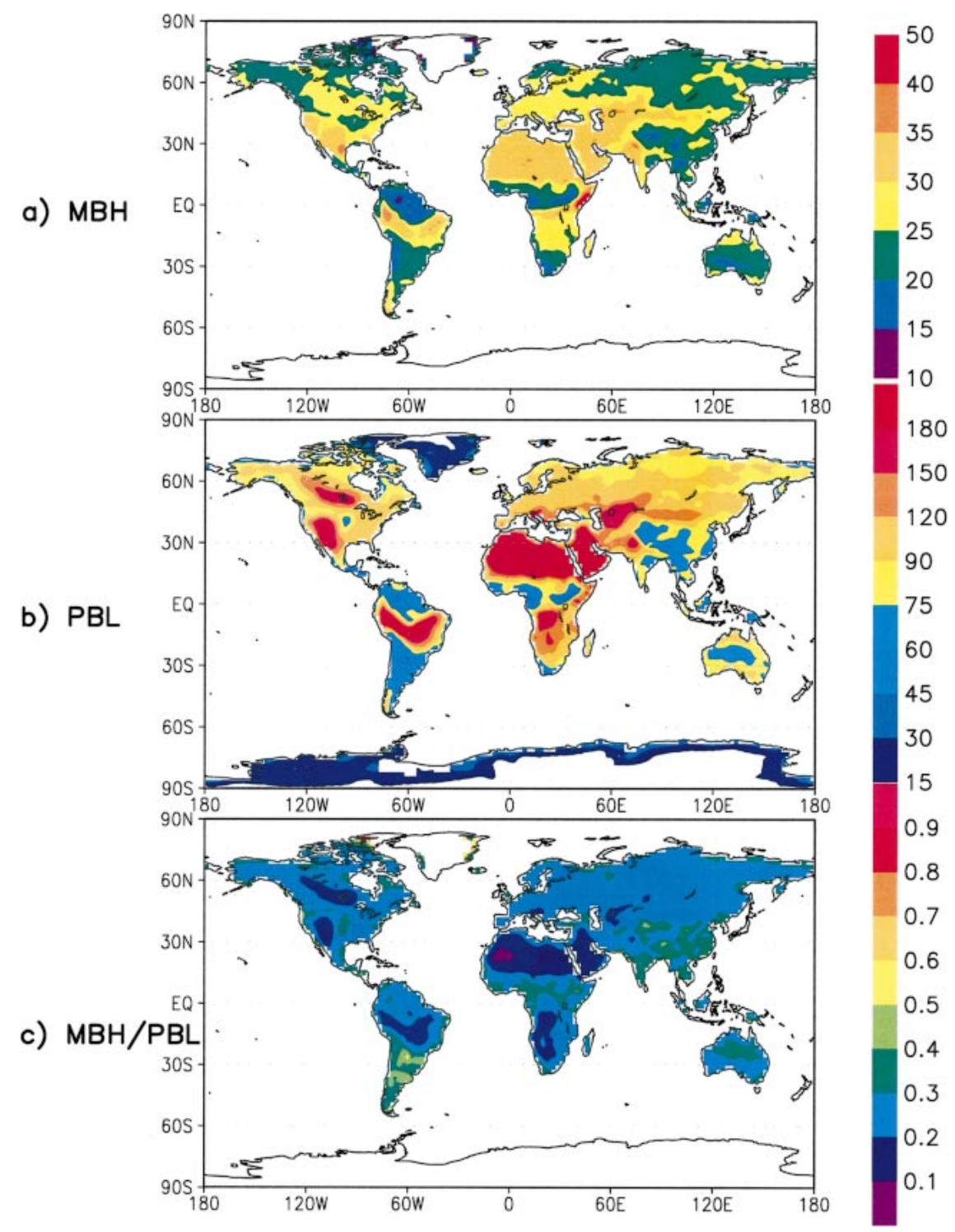

FIG. 5. The same as in Fig. 4 except for Jun-Jul-Aug.

latitude of maximum $\mathrm{MBH}$ in the Northern Hemisphere traverses poleward in the wintertime and equatorward in summertime. This can be seen in the DJF and JJA $\mathrm{MBH}$ fields, where, for example, over Asia, the location of high $\mathrm{MBH}$ values (shaded orange in Fig. 4, 30-35 $\mathrm{mb}$ ) is near $60^{\circ} \mathrm{N}$ latitude in DJF, and moves south to near $40^{\circ} \mathrm{N}$ in JJA (Fig. 5). The same summer-winter traverse can be seen in Africa and South America from DJF to JJA, but in the Southern Hemisphere the poleward shift occurs in the summertime (December).

To gain some further insight into the relationship between the $\mathrm{MBH}$ and the PBL, we examine scatterplots of seasonal mean $\mathrm{MBH}$ versus PBL for all land points. Figure 6 shows this plot for JJA. In general, the $\mathrm{MBH}$ increases with PBL height, except for high (greater than $200 \mathrm{mb}$ ) PBL values, where there is a leveling off of the MBH. These high PBL values occur over desert areas, where the variability of the surface vegetation is small (90\% desert and $10 \%$ broadleaf shrubs), and in a small area in the Amazon, the behavior of which is examined later in this paper. Although there is a linear trend between $\mathrm{MBH}$ and PBL for the lower PBL values, the spread about the representative line is greater than two standard deviations. This spread indicates that the $\mathrm{MBH}$ does not depend simply on PBL height, but is the result of a more complex interplay among different physical processes. Similar behavior was observed in DJF (not shown).

We examined the involvement of the other physical processes in determining the MBH by examining similar scatterplots for other variables. Figure 7 shows the scatterplot of JJA $\mathrm{MBH}$ against $T_{c}$. It shows that the $\mathrm{MBH}$ 


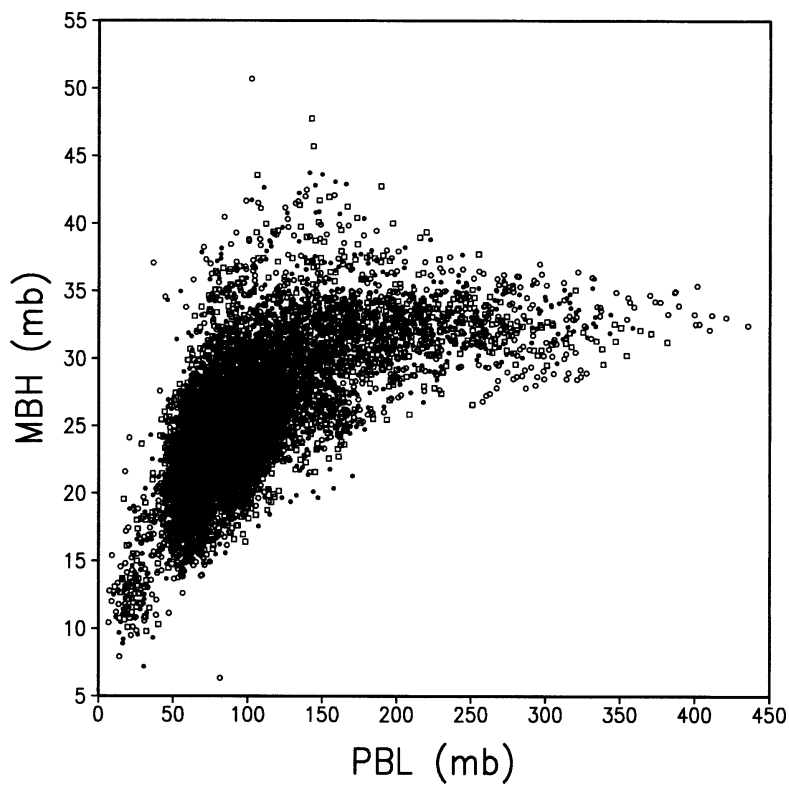

FIG. 6. MBH vs PBL scatterplot (mb) for Jun, Jul, and Aug monthly mean values over all land points.

increases with $T_{c}$, with $\mathrm{MBH}$ values ranging from near 10 to near $45 \mathrm{mb}$ over a temperature range of 260 to $310 \mathrm{~K}$. The exception to this behavior is a small group of points, colored in red, at relatively warm canopy temperatures (just below $300 \mathrm{~K}$ ), for which the $\mathrm{MBH}$ values are near $10-15 \mathrm{mb}$, rather than closer to $30 \mathrm{mb}$, as the global trend would have dictated. These points are all characterized as tropical rain forest, and the relationship between $\mathrm{MBH}$ and $T_{c}$ over this type of densely forested terrain is markedly different from the relationship over other types of soil and vegetation. For these points, the MBH varies much more rapidly with temperature and ranges from 13 to 42 mb over a $T_{c}$ range of 295 to $300 \mathrm{~K}$. In the tropical rain forests, the low $\mathrm{MBH}$ (and lower $T_{c}$ ) points are characterized by very high levels of evaporation, and the high $\mathrm{MBH}$ (and higher $T_{c}$ ) points have almost no evaporation. We illustrate this behavior with contour plots of $\mathrm{MBH}, T_{c}$, and turbulent surface fluxes over the Amazon region, Figs. 8a-d, where we see that the areas of high $\mathrm{MBH}$ (Fig. 8a) correspond to the areas of low evaporation (Fig. 8c). At the lower temperatures, the evaporation levels suppress the sensible heat flux (available energy at the surface is released through evaporation, primarily through evapotranspiration) and the $\mathrm{MBH}$ is lower. In contrast, at the higher temperatures (beyond the modelspecified threshold), the evaporation is suppressed to conserve leaf and plant moisture, the sensible heat flux is increased, and the $\mathrm{MBH}$ is higher. This correspondence to the sensible heat flux is seen in Fig. 8d.

Similar scatterplots of $\mathrm{MBH}$ versus sensible heat flux (not shown) show that the global relationship between the $\mathrm{MBH}$ and the sensible heat flux is linear in character, with $\mathrm{MBH}$ increasing with sensible heat. This is as ex-

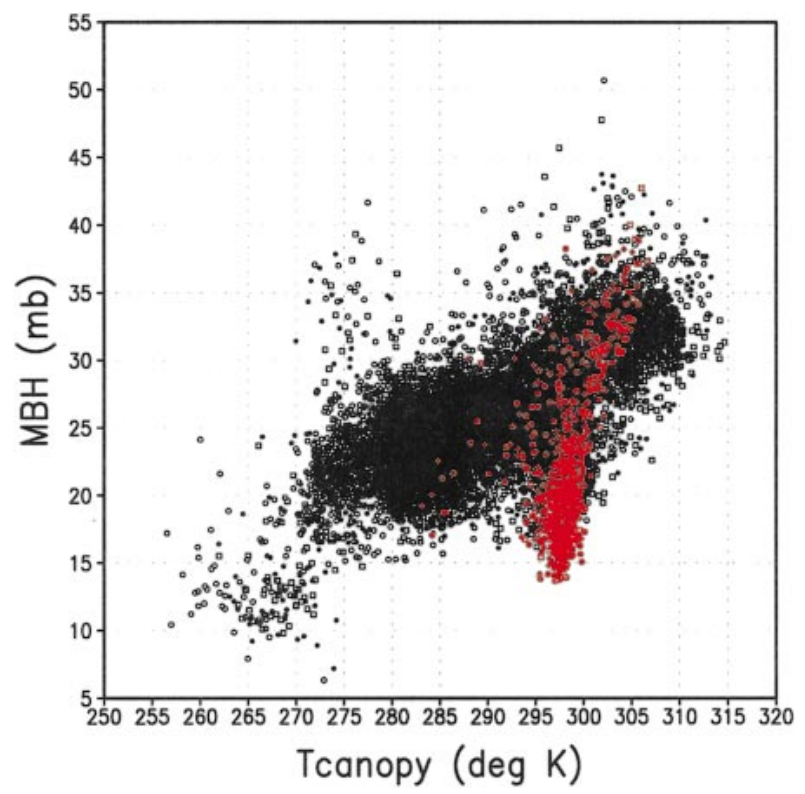

FIG. 7. MBH (mb) vs canopy temperature (K) scatterplot for Jun, Jul, and Aug monthly mean values over all land points. Points over tropical rain forests are colored red.

pected, given that the sensible heat flux is the major contributor to the boundary layer bouyancy and turbulence that determines the PBL height. This relationship between $\mathrm{MBH}$ and sensible heat flux is independent of the choice of surface variability used to define the $\mathrm{MBH}$. The linear relationship holds even when the $\mathrm{MBH}$ is defined based on the variability of surface latent heat flux or momentum flux.

In addition to a relationship between the $\mathrm{MBH}$ and the local characteristics of the turbulence, the behavior of the MBH also depends on the type and variability of surface vegetation. We demonstrate this relationship with a year-long time series of the $\mathrm{MBH}$ and PBL at two characteristic points in the region of the IndianAsian monsoon. These points and their vegetation characteristics are indicated in Fig. 9, which shows a shaded map of the fractional area covered by vegetation types other than the dominant type. This is a measure of the variability of vegetation in the grid box. The first point is in southern Asia $\left(16^{\circ} \mathrm{N}, 100^{\circ} \mathrm{E}\right)$ and is characterized by $60.0 \%$ ground cover, $14.8 \%$ broadleaf evergreen trees, $14.3 \%$ broadleaf deciduous trees, $8.9 \%$ bare soil, and $2.0 \%$ dwarf trees. This point has the higher offdominant percent of coverage of the two points, and is also differentiated from the other point by the presence of the deciduous trees. The second point is on the Indian subcontinent $\left(12^{\circ} \mathrm{N}, 77.5^{\circ} \mathrm{E}\right)$ and is characterized by $80.5 \%$ ground cover, $9.8 \%$ bare soil, $4.7 \%$ dwarf trees, $3.1 \%$ broadleaf deciduous trees, and $1.9 \%$ broadleaf evergreen trees. This point has the lower off-dominant fraction and almost no deciduous trees. Both of these points are in climatologically similar regimes, governed by a monsoonal flow and relatively dry in the winter- 

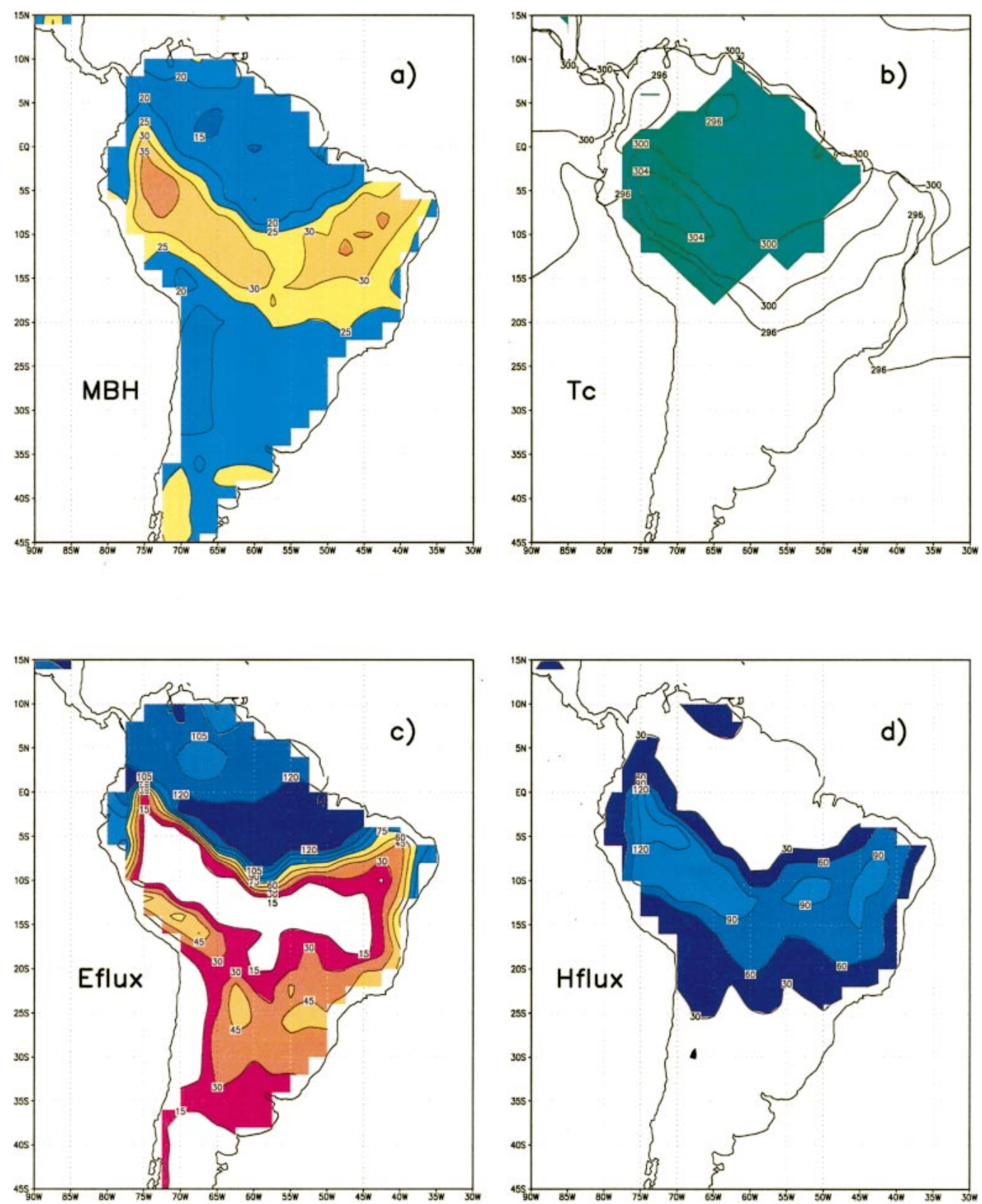

FIG. 8. Jun, Jul, Aug seasonal mean contour plots for South America. (a) MBH in mb, contour interval is $5 \mathrm{mb}$; (b) canopy temperature in $\mathrm{K}$, contour interval is $4 \mathrm{~K}$; (c) latent heat flux in $\mathrm{W} \mathrm{m}^{-2}$, contour interval is $15 \mathrm{~W} \mathrm{~m}^{-2}$; and (d) sensible heat flux in $\mathrm{W} \mathrm{m}^{-2}$, contour interval is $30 \mathrm{~W} \mathrm{~m}^{-2}$. The area shaded green in (b) corresponds to the area covered by tropical rain forest.

time. Figure 10 shows a 1- and 30-day running mean of the PBL (Figs. 10a and 10c) and MBH (Figs. 10b and 10d) for the two points. The PBL at both points shows a robust seasonal cycle, high (near $140 \mathrm{mb}$ ) in the springtime and low (near $40 \mathrm{mb}$ ) in the winter. The $\mathrm{MBH}$, however, exhibits distinctly different behavior between the two points. Figure 10b shows that the point with higher vegetation variability and the higher amount of deciduous trees $\left(16^{\circ} \mathrm{N}, 100^{\circ} \mathrm{E}\right)$ has a marked season- ality in the $\mathrm{MBH}$, ranging from near $40 \mathrm{mb}$ in the late spring (lagging behind the PBL by a month) to approximately $20 \mathrm{mb}$ in the fall. In contrast, the other point $\left(12^{\circ} \mathrm{N}, 77.5^{\circ} \mathrm{E}\right)$ shows no such seasonality in the $\mathrm{MBH}$, as seen in Fig. 10d. The value of the MBH is nearly constant at $25 \mathrm{mb}$ throughout the year.

Examination of time series of some other relevant meteorological fields aids in understanding the connection between the presence of deciduous trees and the 


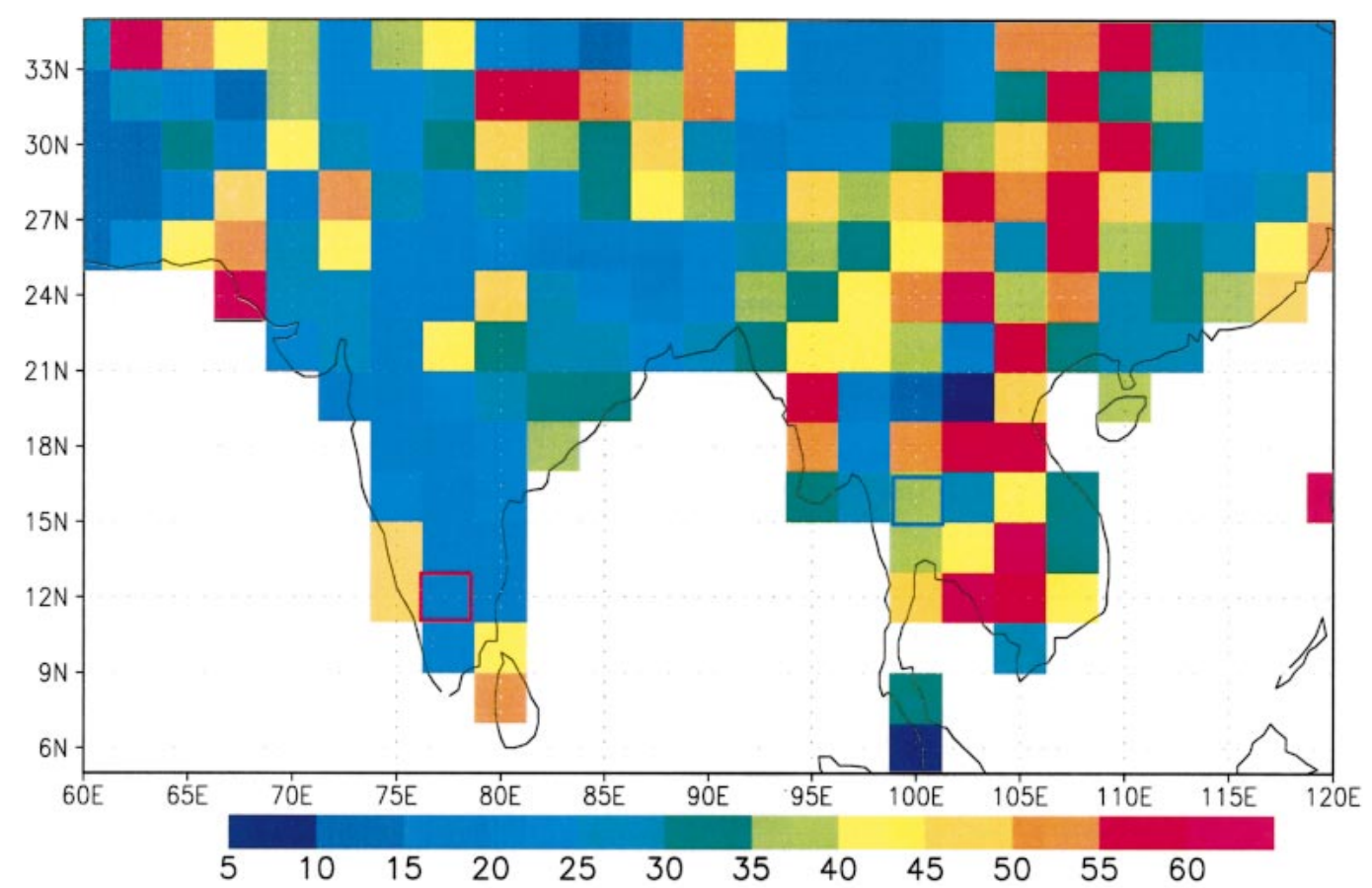

$(77.5 \mathrm{E}, 12 \mathrm{~N})$

$(100 \mathrm{E}, 16 \mathrm{~N})$

$80.5 \%$ Groundcover

9.8\% Bare Soil

4.7\% Dwarf Trees

3.1\% Broadleaf Deciduous

1.9\% Broadleaf Evergreen
$60 \%$ Groundcover

14.8\% Broadleaf Evergreen

14.3\% Broadleaf Deciduous

\section{9\% Bare Soil}

\section{0\% Dwarf Trees}

FIG. 9. Percent of grid box covered by nondominant vegetation for southern Asia. The two illustrated grid points are indicated by the blue and red boxes and by the description of vegetation characteristics.

MBH seasonality. Figure 11 shows the 1- and 30-day running means of the latent heat flux (Figs. 11a,b), canopy temperature (Figs. 11c,d), precipitation (Figs. $11 \mathrm{e}, \mathrm{f}$ ), and sensible heat flux (Figs. 11g,h) for both points. The similarity of the precipitation patterns (Figs. $11 \mathrm{e}, \mathrm{f})$ and canopy temperature patterns (Figs. 11c,d) at both points demonstrates that they are in the same climate regime. Figures 11a,b show that the latent heat flux over the point with deciduous trees is almost completely suppressed during the months when the trees have no leaves. This results in a sharper increase in latent flux during the springtime. In contrast, at $12^{\circ} \mathrm{N}$, $77.5^{\circ} \mathrm{E}$ (the point with no deciduous trees and low surface variability) the latent flux is small in wintertime but is not completely suppressed, and the contrast be- tween winter and springtime levels is not as marked. Consistent with the behavior of the latent heat flux, Figs. $11 \mathrm{~g}$, h show that the sensible heat flux at $16^{\circ} \mathrm{N}, 100^{\circ} \mathrm{E}$ is higher in wintertime than the sensible heat at $12^{\circ} \mathrm{N}$, $77.5^{\circ} \mathrm{E}$.

Examination of other points in this climatological regime revealed that the presence of deciduous trees alone is insufficient to generate a high seasonality in the $\mathrm{MBH}$. High surface variability is necessary as well. For example, the grid box at $10^{\circ} \mathrm{N}, 77.5^{\circ} \mathrm{E}$ has deciduous trees but low surface variability, is characterized by $80.0 \%$ ground cover, $9.0 \%$ broadleaf deciduous trees, $10.0 \%$ bare soil, and $1.0 \%$ dwarf trees, and shows no seasonality in the $\mathrm{MBH}$, despite a marked seasonality in the PBL. In other words, the variability and the presence 

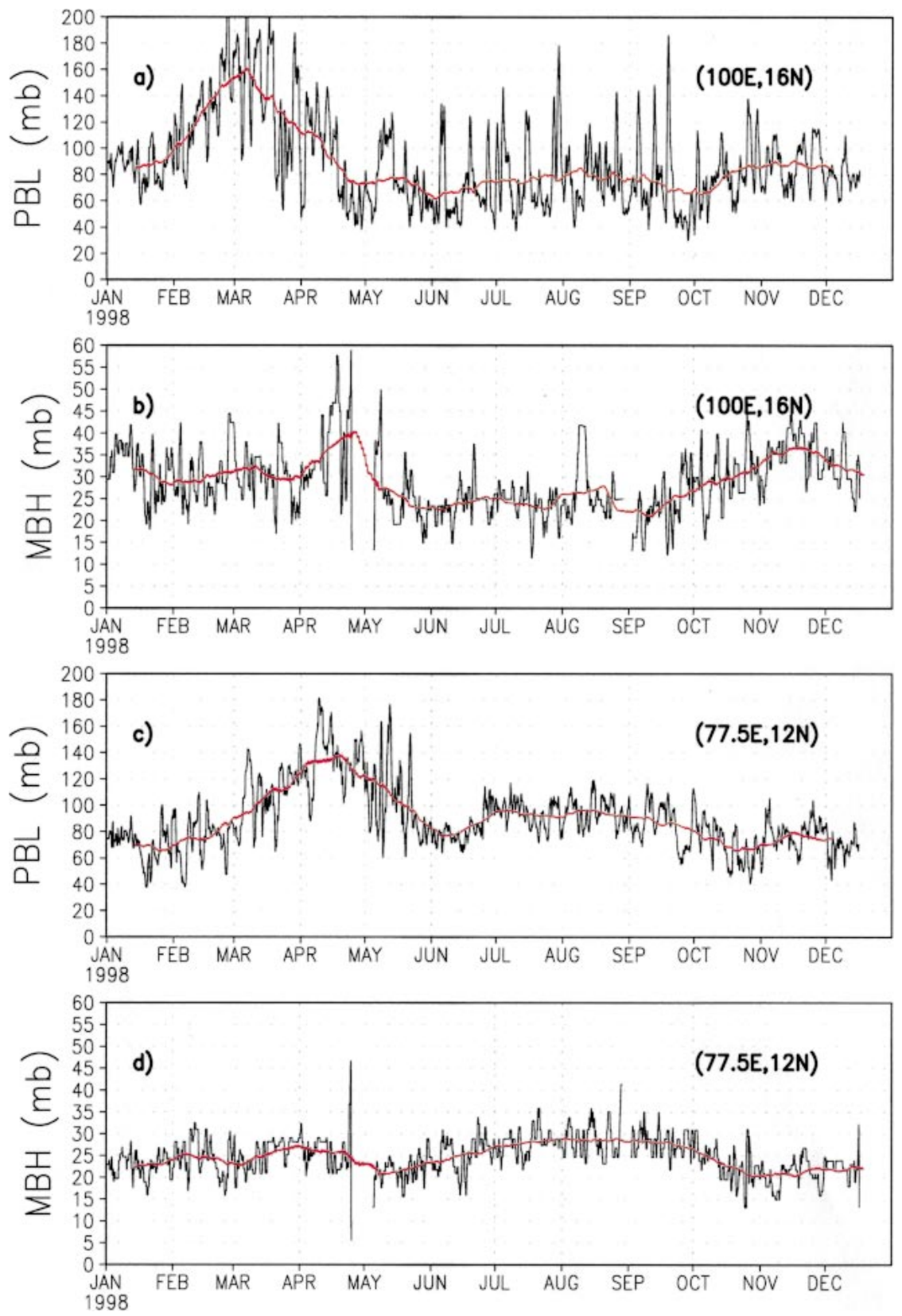

FIG. 10. Time series of PBL and MBH height in $\mathrm{mb}$ for $100^{\circ} \mathrm{E}, 16^{\circ} \mathrm{N}$, (a) and (b), respectively, and for $77.5^{\circ} \mathrm{E}, 12^{\circ} \mathrm{N}$, (c) and (d), respectively. Each panel contains 1- and 30-day running means.

of deciduous trees is needed for the MBH to exhibit a strong seasonal cycle.

\section{Summary and conclusions}

The study of the extended mosaic (EM) technique presented here is aimed at developing a better tool to simulate and understand the direct (aggregation) effects of the interactions between a heterogeneous land surface and the climate. This technique allows the influence of the surface heterogeneities to extend upward into the turbulent boundary layer by assuming that the conceptualization of surface heterogeneity as a mosaic of independent vegetation stands is applicable throughout the atmospheric column. The additional degree of freedom of the system, that of allowing the vertical extent of the influence of surface heterogeneities to be determined internally, has the potential to afford a better characterization of the land-atmosphere interactions.

Simulations with this technique revealed that the profiles of turbulent fluxes over each tile in a grid box differ near the ground and become homogenized at some level 

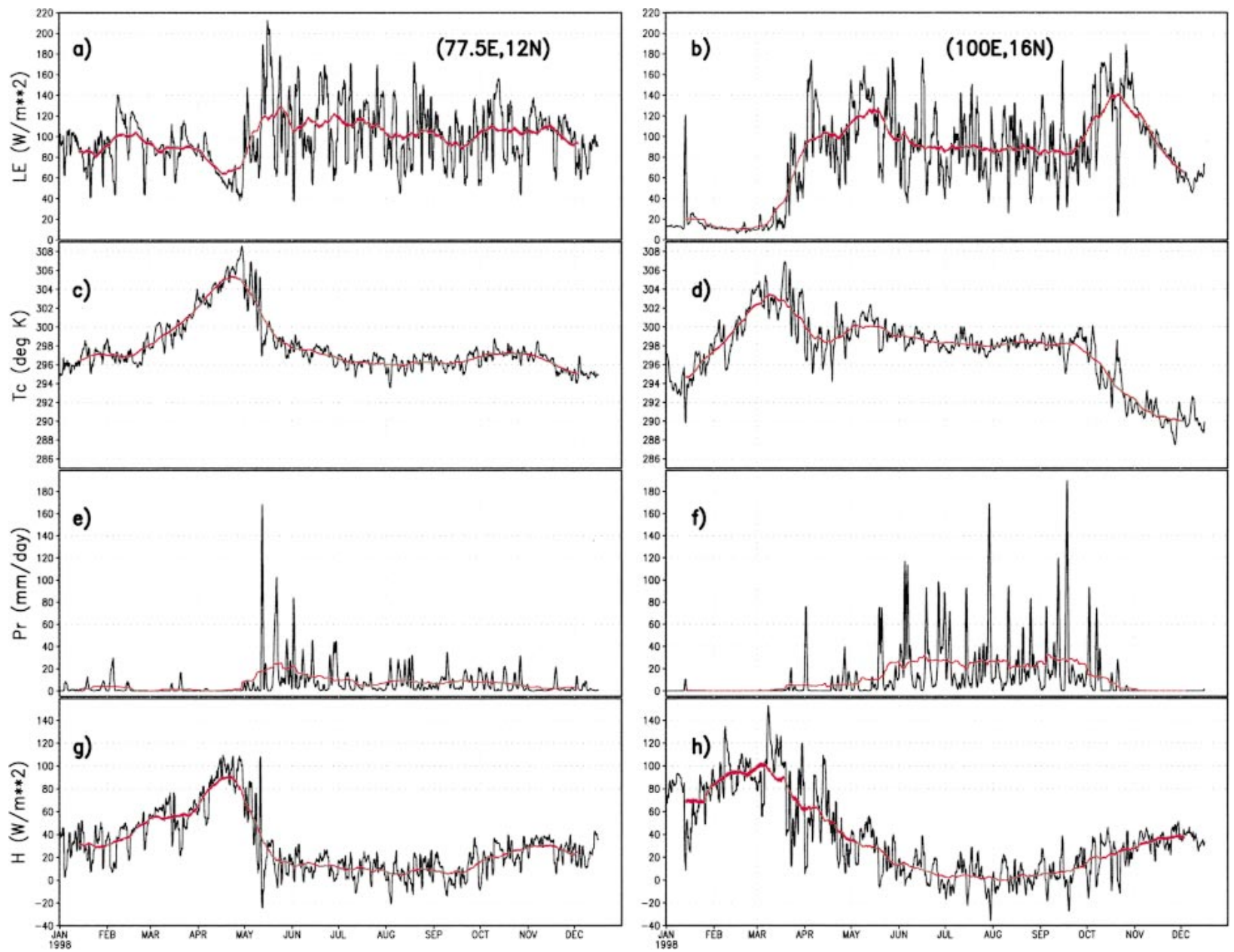

FIG. 11. Time series of meteorological fields for $77.5^{\circ} \mathrm{E}, 12^{\circ} \mathrm{N}$ and $100^{\circ} \mathrm{E}, 16^{\circ} \mathrm{N}$. (a), (c), (e), (g) Latent heat flux in $\mathrm{W}$ m ${ }^{-2}$, canopy temperature in $\mathrm{K}$, precipitation in $\mathrm{mm} \mathrm{day}^{-1}$, and sensible heat flux in $\mathrm{W} \mathrm{m}^{-2}$, respectively, for $77.5^{\circ} \mathrm{E}, 12^{\circ} \mathrm{N}$. (b), (d), (f), (h) The corresponding plots for $100^{\circ} \mathrm{E}, 16^{\circ} \mathrm{N}$. Each panel contains 1 - and 30-day running means.

aloft. This behavior allows the definition of a model blending height $(\mathrm{MBH})$ as the level where the homogenization takes place. We emphasize that the EM algorithm does not require that the turbulent fluxes become homogenized, hence the blending is a result of the simulations with EM. The MBH varies between 50 and $500 \mathrm{~m}$, and is generally about one-third of the PBL height. The exact ratio depends on meteorological conditions, location, and the amount of variability in the land scene type.

Examination of the relationship among the $\mathrm{MBH}$ and other meteorological variables shows that seasonal mean values of the MBH and PBL height exhibit similar spatial patterns in warm and dry regions, and differ more in the Northern Hemisphere wintertime and over relatively homogeneous terrain. The $\mathrm{MBH}$ increases gradually with PBL height, sensible heat flux, and canopy temperature through moderate to warm values, although the spread of values about these trends is substantial. This spread is indicative of the complexity of the de- pendence of the $\mathrm{MBH}$ on local conditions, and several examples of this complexity were presented.

The dependence of the $\mathrm{MBH}$ on the canopy temperature increases dramatically for temperatures near 300 $\mathrm{K}$. This is related to the behavior of the latent heat flux, which is high for temperatures just below $300 \mathrm{~K}$, and is suppressed (infinite stomatal resistance) when the canopy temperature exceeds a vegetation-dependent threshold (usually near $300 \mathrm{~K}$ ). When the evaporation is high, the $\mathrm{MBH}$ is low, and when the available surface energy is released as sensible rather than latent heat flux, the $\mathrm{MBH}$ is elevated. This results in the sharp increase of $\mathrm{MBH}$ with canopy temperature in regions where evaporation dominates the surface energy balance.

The MBH was also found to depend on the variability and types of underlying vegetation. The presence of deciduous trees in the mix of tiles, in addition to high levels of variability in scene type, was shown to be associated with in an increased seasonality of the MBH. An example of this behavior was presented by exam- 

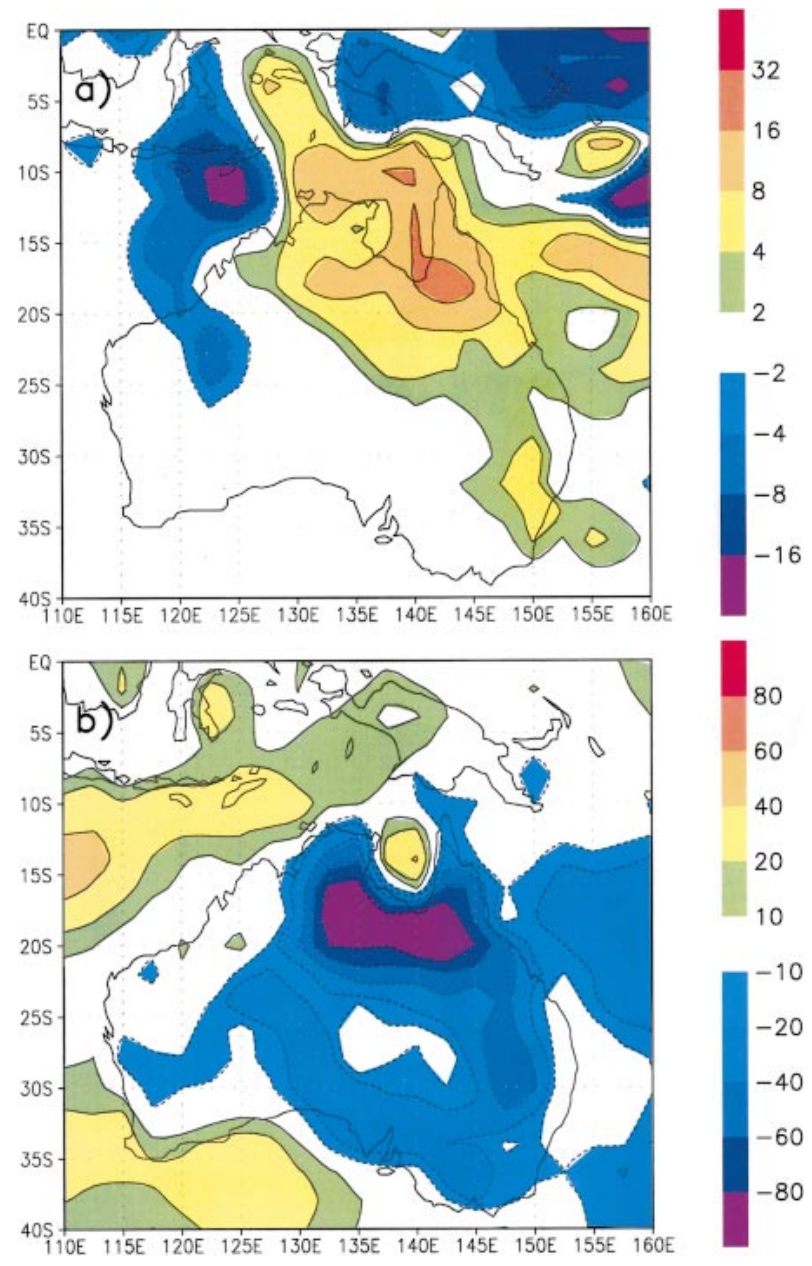

FIG. 12. (a) Jan avg difference (EM-M) in precipitation in $\mathrm{mm}$ day $^{-1}$ over Australia. (b) Jan avg difference planetary boundary layer thickness in $\mathrm{mb}$

ining two grid boxes in similar climate regimes (monsoonal circulation), where the annual cycle of evaporation (and sensible heat flux) is significantly enhanced at the grid box that contains deciduous trees.

In this study we have presented the EM technique for modeling the coupling at the land surface-atmosphere interface. Although this yielded a physically consistent depiction of the relationship between the MBH and the turbulent boundary layer overlying a heterogeneous surface, the impact on model simulations and the robustness of the behavior of the MBH still needs to be investigated. We are currently investigating the impact of the EM technique on simulated land-atmosphere feedbacks by comparing parallel simulations with EM and the more standard mosaic approach (M), and evaluating any differences in the context of available climatological observations. Preliminary examination of the EM versus $\mathrm{M}$ comparisons indicates that there is an impact from modeling the aggregation effects differently. An illustrative example is the EM-M difference in January monthly mean precipitation and PBL height over Aus- tralia, shown in Fig. 12. The EM simulation has larger precipitation amounts over the northern land areas, and less over the ocean (Fig. 12a). This constitutes an increased excursion of the monsoon precipitation over the land, and represents a relative improvement in the simulated precipitation as compared to the Global Precipitation Climatology Project data of Huffman et al. (1997). Figure 12b shows that the PBL height is lower in EM in the regions where the precipitation is higher. This connection in EM between lower boundary layer heights over wetter, cooler areas, and increased precipitation due to higher equivalent potential temperature, is similar to the connection between wet domains and precipitation suggested by the work reported in Cotton and Pielke (1992). This behavior demonstrates a mechanism by which the local impact of modeling differences may affect the mean climate elsewhere.

We also plan to evaluate the behavior of EM by comparisons of the MBH against observational and highresolution model estimates of the blending height. To facilitate these comparisons against this type of verification data, and to better understand the mechanisms at work, we will further examine the details of the behavior of the MBH and attempt to develop a scaling relationship for the dependence on local and climate variables. An additional outstanding problem for consideration relates to the parameterization of dynamical effects (due to the generation of mesoscale circulations) of heterogeneity on the grid scale. Several studies with mesoscale models (Avissar and Chen 1993; Zeng and Pielke 1995; Lynn et al. 1995) have shown that fluxes associated with the mesoscale circulations may be important near the top of the boundary layer, but observational evidence of mesoscale circulations (Doran et al. 1995) and of their absence (Hubbe et al. 1997) leaves open the question of their impact on the regional or climate scale. A scheme that includes these effects as well as the aggregation effects addressed by this paper would provide a more complete description of the impact of land surface heterogeneity on the simulated climate in global models.

Acknowledgments. AM gratefully acknowledges discussions with Max Suarez, Mark Helfand, and Randal Koster that were helpful in the development of the extended mosaic technique. Sharon Nebuda also provided invaluable day-to-day support during the development stages of the technique. The authors are grateful for the general support and encouragement given to us by Paul Houser and Randal Koster for the ideas presented in this paper. The computing resources for these experiments were provided by the NASA Data Assimilation Office. AM is supported by NASA Earth System Science Graduate Fellowship ESS/00-0000-0016.

\section{REFERENCES}

Avissar, R., and R. Pielke, 1989: A parameterization of heterogeneous land surfaces for atmospheric numerical models and its impact on regional meteorology. Mon. Wea. Rev., 117, 2113-2136. 
equations for mesoscale kinetic energy and mesoscale (subgrid scale) fluxes for large-scale atmospheric models. J. Atmos. Sci., 50, 3751-3774.

- , and T. Schmidt, 1998: An evaluation of the scale at which ground-surface heat flux patchiness affects the convective boundary layer using large-eddy simulations. J. Atmos. Sci., 55, 2666-2689.

Bringfelt, B., M. Heikimheimo, N. Gustafsson, V. Perov, and A. Lindroth, 1999: A new land-surface treatment for HIRLAM-Comparisons with NOPEX measurements. Agric. For. Meteor., 989, 239-256.

Brutsaert, W., 1998: Land-surface water vapor and sensible heat flux: Spatial variability, homogeneity, and measurement scales. Water Resour. Res., 34, 2233-2442.

Chen, F., and R. Avissar, 1994: Impact of land-surface moisture variability on local shallow convective cumulus and precipitation in large-scale models. J. Appl. Meteor., 33, 1382-1401.

Claussen, M., 1995: Flux aggregation at large scales: On the limits of validity of the concept of blending height. J. Hydrol., 166 , 371-382.

Cotton, W. R., and R. A. Pielke, 1992: Human Impacts on Weather and Climate. Cambridge University Press, 288 pp.

DeFries, R. S., and J. R. G. Townshend, 1994: NDVI-derived lan cover classification at global scales. Int. J. Remote Sens., 15 3567-3586.

Dickinson, R., A. Henderson-Sellers, P. Kennedy, and M. Wilson, 1986: Biosphere-Atmosphere Transfer Scheme (BATS) for NCAR Community Climate Model. Tech. Note TN 275+STR, National Center for Atmospheric Research, Boulder, CO, 69 pp.

Doran, J. C., W. J. Shaw, and J. M. Hubbe, 1995: Boundary laye characteristics over areas of inhomogeneous surface fluxes. $J$. Appl. Meteor., 34, 559-571.

Dorman, J. L., and P. J. Sellers, 1989: A global climatology of albedo, roughness length and stomatal resistance for atmospheric genera circulation models as represented by the Simple Biosphere Model (SiB). J. Appl. Meteor., 28, 833-855.

Entekhabi, D., and P. S. Eagleson, 1989: Land surface hydrology parameterization for atmospheric general circulation models including subgrid scale spatial variability. J. Climate, 2, 816-831.

Giorgi, F., and R. Avissar, 1997: Representation of heterogeneity effects in earth system modeling: Experience from land surface modeling. Rev. Geophys., 35, 413-438.

Helfand, H. M., and J. C. Labraga, 1988: Design of a non-singular level 2.5 second-order closure model for the prediction of atmospheric turbulence. J. Atmos. Sci., 45, 113-132.

—, and S. D. Schubert, 1995: Climatology of the simulated Great Plains low-level jet and its contribution to the continental moisture budget of the United States. J. Climate, 8, 784-806.

Hess, G. D., and B. J. McAvaney, 1998: Realisability constraints for land surface schemes. Global Planet. Change, 19, 241-245.
Hubbe, J. M., J. C. Doran, J. C. Liljegren, and W. J. Shaw, 1997: Observations of spatial variations of boundary layer structure over the Southern Great Plains Cloud and Radiation Testbed. J. Appl. Meteor., 36, 1221-1231.

Huffman, G. J., and Coauthors, 1997: The Global Precipitation Climatology Project (GPCP) Combined Precipitation Dataset. Bull. Amer. Meteor. Soc., 78, 5-20.

Koster, R. D., and M. J. Suarez, 1992a: A comparitive analysis of two land surface heterogeneity representations. J. Climate, 5, $1379-1390$

_ mate models as a composite of independant vegetation stands. J. Geophys. Res., 97, 2697-2715.

Lynn, B. H., F. Abramopoulos, and R. Avissar, 1995: Using similarity theory to parameterize mesoscale heat fluxes generated by landscape discontinuities in GCMs. J. Climate, 8, 932-951.

Mahrt, L., 1996: The bulk aerodynamic formulation over heterogeneous surfaces. Bound.-Layer Meteor., 78, 87-119.

_ 2000: Surface heterogeneity and vertical structure of the boundary layer. Bound.-Layer Meteor., 96, 33-62.

Mason, P. J., 1988: The formation of areally-averaged roughness length. Quart. J. Roy. Meteor., Soc., 114, 399-420.

Mölders, N., A. Raabe, and G. Tetzlaff, 1996: A comparison of two strategies on land surface heterogeneity used in a mesoscale $\beta$ meteorological model. Tellus, 48A, 733-749.

Molod, A., 1999: The land surface component in GEOS: Model formulation. DAO Office Note 1999-03, Office Note Series on Global Modeling and Data Assimilation, Goddard Space Flight Center, Greenbelt, MD, 21 pp.

_ _ and H. Salmun, 2002: A Global assessment of the mosaic approach to modeling land surface heterogeneity. J. Geophys. Res., 107, 4217, doi:10.1029/2001JD000588.

Parlange, M. B., and G. Katul, 1995: Watershed scale shear stress from tethersonde wind profile measurements under near neutral and unstable atmospheric stability. Water Resour. Res., 31, 961968.

Sellers, P. J., Y. Mintz, Y. C. Sud, and A. Dalcher, 1986: A Simple Biosphere Model ( $\mathrm{SiB}$ ) for use within general circulation models. J. Atmos. Sci., 43, 505-531.

Viterbo, P., and A. C. M. Beljaars, 1995: An improved land surface parameterization scheme in the ECMWF Model and its validation. J. Climate, 8, 2716-2748.

Wieringa, J., 1986: Roughness-dependent geographical interpolation of surface wind speed averages. Quart. J. Roy. Meteor. Soc., 112, 867-889.

Yamada, T., 1977: A numerical simulation of pollutant dispersion in a horizontally-homogeneous atmospheric boundary layer. Atmos. Environ., 11, 1015-1024.

Zeng, X., and R. A. Pielke, 1995: Landscape-induced atmospheric flow and its parameterization in large-scale numerical models. J. Climate, 8, 1156-1177. 